\title{
Derivation of refraction statics solution for 3D seismic data in an onshore prospect Niger Delta field
}

\author{
Okechukwu Frank Adizua ${ }^{1,2}$, Kenechukwu Emmanuel Anakwuba ${ }^{2}$, \\ Ajana Godwin Onwuemesi ${ }^{2}$ \\ ${ }^{1}$ University of Port Harcourt, Faculty of Science, Department of Physics (Applied Geophysics Option); River State, Nigeria; \\ e-mail: okechukwu.adizua@uniport.edu.ng (correspondingauthor) \\ ${ }^{2}$ Nnamdi Azikiwe University, Faculty of Physical Sciences, Department of Geological Sciences, Awka, Anambra State, Nigeria
}

(C) 2019 Authors. This is an open access publication, which can be used, distributed and reproduced in any medium according to the Creative Commons CC-BY 4.0 License requiring that the original work has been properly cited.

Received: 08 March 2019; accepted: 03 June 2019; first published online: 30 June 2019

\begin{abstract}
The near-surface imaging and characterization of an onshore prospect field in the Niger Delta was successfully carried out in a previous study (Adizua et al. 2019) using an integrated approach of combining inversion of refracted arrivals and uphole measurements. The output of that study which revealed the layer characteristics of the near-surface $(0-500 \mathrm{~m})$ over the prospect field is now being used as a starting model to derive a complete refraction statics solution to be adapted for processing the 3D seismic dataset from the prospect field. The complete statics solution derived included the field or datum statics, refraction statics, and the $1^{\text {st }}$ and $2^{\text {nd }}$ residual statics which addressed the unresolved and remnant spatial long and short wavelength statics effect on the traces across the investigated field. The comprehensive solution was then incorporated into a PROMAX ${ }^{\mathrm{TM}}$ routine and applied to the seismic datasets using appropriate flow commands to perform the statics correction procedure. The outcome of the derived and implemented statics correction was demonstrated on shot gathers from the field in FFID configuration. Results from the several shot gathers analyzed after the application of the statics correction across the field showed that traces were adjusted back to their appropriate positions. The reflectors became better aligned and assumed a near-hyperbolic pattern which is a positive indication that the derived and applied refraction statics solution was the most appropriate for the dataset.
\end{abstract}

Keywords: near-surface imaging, near-surface characterization, starting model, field or datum statics, refraction statics, $1^{\text {st }}$ and $2^{\text {nd }}$ residual statics, FFID configuration, alignment of reflectors

\section{INTRODUCTION}

It is imperative that refraction statics (also called statics correction) be correctly derived and applied in seismic processing flow for a number of reasons; they place both source and receiver at a common or constant datum plane, they ensure that reflection events on intersecting lines will be at the same time, thereby eliminating undesirable scenarios of the mis-tie of reflection events
(Marsden 1993a) and they also ensure the repeatability of seismic recording (Russell 1990). In addition to the aforementioned factors, correctly derived and implemented refraction statics would also improve upon the quality of further processing steps like velocity analysis, stacking and migration. The impact of the implementation of refraction statics on the stacking and migration quality of seismic reflection data would be the focus of a subsequent study. In onshore seismic 
data acquisition programs, the often encountered, complex near-surface geologic conditions, such as weathered layers, uneven and rugged topography, nature and human induced interferences influences and degrades the quality of the recorded data due to the multiple paths of seismic waves on the surface (Zhu et al. 2014). The undesirable effects caused by the near-surface conditions therefore have to be remedied, and achieving this adequately is frequently a daunting challenge (Cox 1999, Keho \& Kelamis 2012, Zhu et al. 2014). The correct derivation and application or implementation of refraction statics is a very practical way to effectively eliminate such undesirable influences that degrades the data quality (Cox 1999, Deere \& Cox 2009).

Statics corrections are basically corrections applied to seismic data to compensate for the effects of variations in elevation, weathering thickness, weathering velocity or reference to a datum (Sheriff 1991). The objective is to determine the reflection arrival times which would have been observed if all measurements were made on a reference datum which usually is considered to be a flat plane with no weathering or low-velocity materials present (Cox 1999). Statics corrections that should be applied in the processing of seismic data should be surface consistent, implying that the corrections should be dependent on the location of the source or receiver but be independent of the source to receiver distance (offset) or time of recording of the data (Cox 1999, Deere 2009). To correctly derive and implement refraction statics for 3D seismic data, a near-surface model with weathering and sub-weathering layer thicknesses and velocities must first be obtained as accurately as possible. This objective has already been successfully achieved in a previous study using a hybrid near-surface imaging approach (Adizua et al. 2019). The result obtained is now to be deployed as a starting model to derive a comprehensive refraction statics solution to be incorporated in the processing workflow of the seismic dataset from the prospect field being investigated to address its statics problem.

The prospect field being investigated is located in the southern part of the Niger Delta Basin, Nigeria. It covers areas in parts of the present-day Rivers and Bayelsa states of Nigeria. Figure 1 is a map of the Niger Delta area showing the approximate location of the study area (marked in red) wherein the prospect field lies.

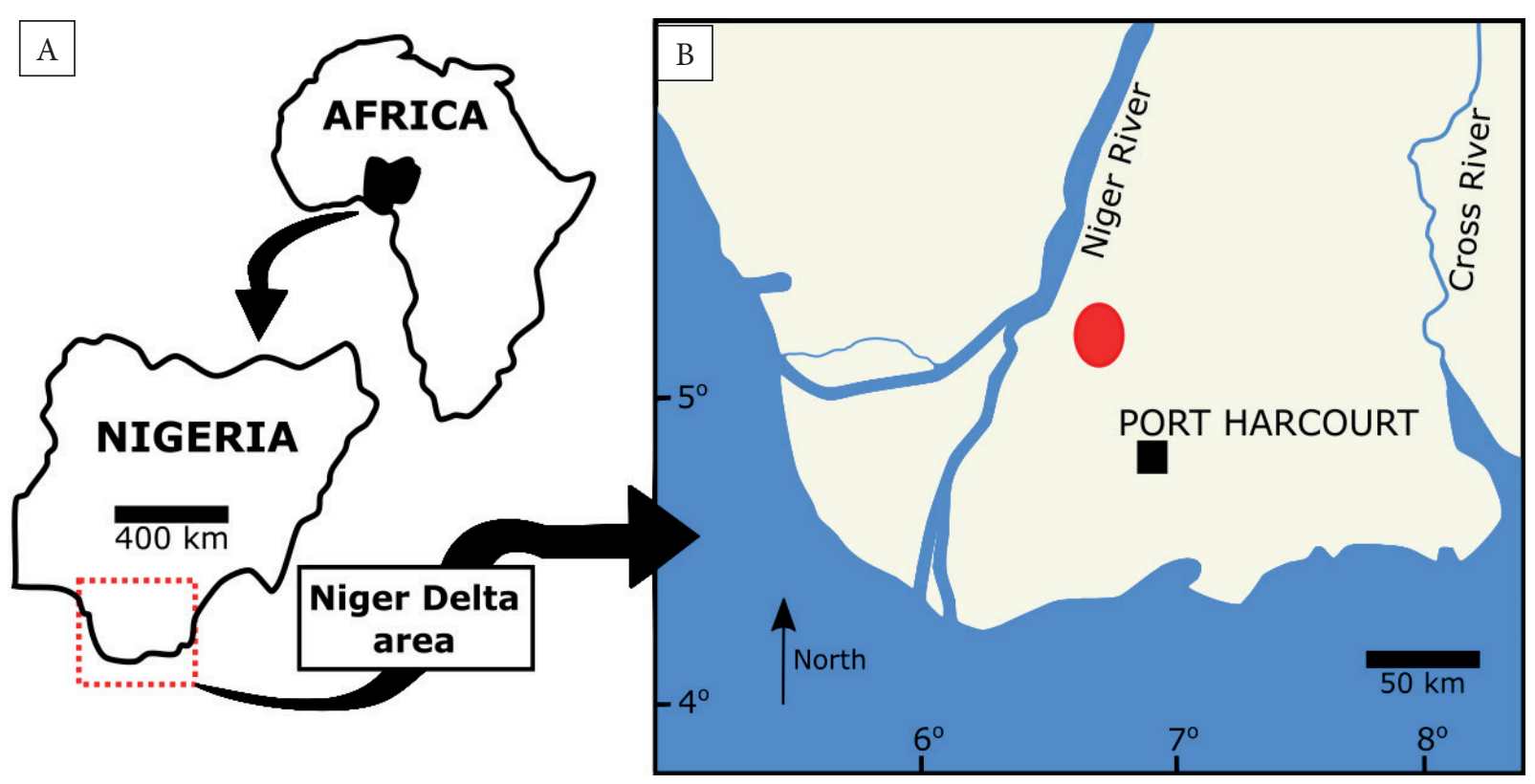

Fig. 1. Map of the Niger Delta area showing location of the study area 
The prospect field covers an extensive area of over $151.3 \mathrm{~km}^{2}$, the terrain of the prospect is predominantly onshore but with a network of rivers, swamps, creeks, and adjoining canals. The vegetation is mainly mangrove. The $3 \mathrm{D}$ seismic acquisition for the prospect was carried in three phases. Each acquisition phase covered approximately 13 swaths. The entire acquisition was done with well over 27,500 shots. The shooting geometry was a symmetric split spread configuration with an offset range from 25 to $6500 \mathrm{~m}$. A Sercel 428 recording instrument was deployed for the acquisition. Before the 3D seismic acquisition, a total of about 50 uphole location points were identified and mapped for uphole shooting across the entire field. The geology of the prospect field is defined by the geology of the Niger Delta Basin. It is a large, arcuate Tertiary prograding sedimentary complex deposited under transitional marine, deltaic and continental environments from the Paleocene in the north to the Recent in the south. It occupies an area lying between longitude $4-9^{\circ} \mathrm{E}$ and latitude $4-6^{\circ} \mathrm{N}$. It is bounded in the east by the Calabar Flank and Abakaliki Trough, in the west by the Benin Flank, in the north by the Anambra Basin and in the south by the Atlantic Ocean. Both the marine and mixed continental depositional environment characterize the Niger Delta Basin of Nigeria (Uko et al. 1992). The Niger Delta covers an area of about $75,000 \mathrm{~km}^{2}\left(28,957 \mathrm{mi}^{2}\right)$ in southern Nigeria. The Niger Delta Basin consists of three main tertiary stratigraphic units overlain by Quaternary deposits (Short \& Stauble 1967). These three subsurface stratigraphic units are the Benin, Agbada, and Akata formations. The Benin formation is predominantly a massive sand sequence, while the Agbada formation is a coastal marine sequence of alternating sand and shale. The Akata formation is the basal unit which consists mainly of marine shale units. The sedimentary thickness of the Niger Delta Basin is over $12 \mathrm{~km}$ and has accumulated over a period of close to 55 million years.

The major focus for the present study is to derive a comprehensive and complete statics solution which would consist of field or datum statics, refraction statics, and residual $\left(1^{\text {st }}\right.$ and $\left.2^{\text {nd }}\right)$ statics for the dataset using the near-surface model previously obtained for the prospect field. The impact of the derived and implemented or applied statics would subsequently be shown on several shot gathers from the field in Field File Identification (FFID) configuration.

\section{UNDERLYING PRINCIPLES AND BACKGROUND THEORIES}

An attempt is made in this section to explain the underlying principles and provide the background theories of the approaches used in obtaining the complete set of statics solution derived and implemented on the seismic datasets acquired from the prospect field to tackle its statics problem.

\section{Field statics}

The concept of field statics, which is also referred to as datum statics or at times - elevation statics, involves the computation and removal of the effect of different source and receiver elevations by introducing a new horizontal plane (reference datum) below the low velocity layer, in order to place or simulate all sources and receivers on this reference plane (Fig. 2) which is usually in most cases below the elevation of the lowest source or receiver.

A replacement velocity $\left(V_{r}\right)$ for the materials between the datum and the source or receiver is needed. This parameter is either assumed from prior knowledge of replacement velocity within an area or by its estimation using either uphole times or direct arrival information. This parameter and other near-surface information like weathering and sub-weathering layer thicknesses and velocities have already been obtained in a previous study (Adizua et al. 2019).

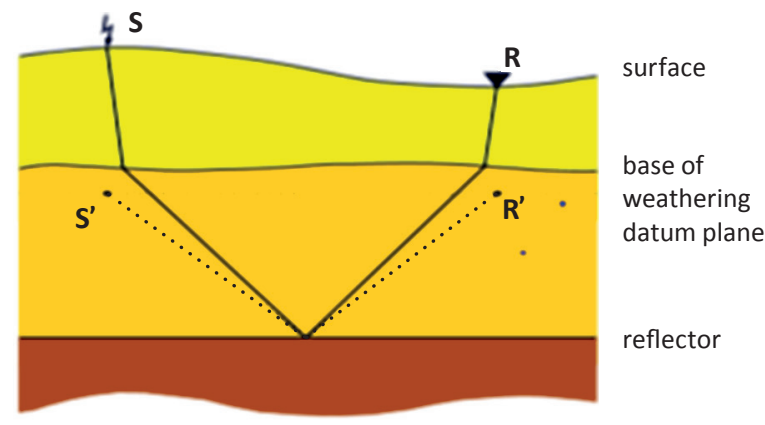

Fig. 2. Scheme of a pseudo-source and receiver location ( $S$ ' and $R^{\prime}$ ) on a reference datum from the actual source $(S)$ and receiver $(R)$ positions on the Earth's surface in the build up to field statics 
The field (datum or elevation) statics $t_{D}$ is given by the expression:

$t_{D}=\frac{\left[\left(E_{S}-Z_{S}-E_{D}\right)+\left(E_{R}-Z_{R}-E_{D}\right)\right]}{V_{r}}$

For the scenario depicted or described by Figure 3.

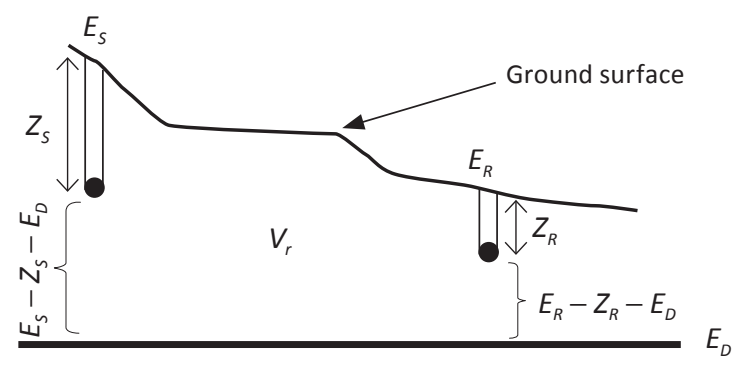

Fig. 3. Schematic illustration of the procedure for the computation of field statics. Explanations: $E_{S}$ - ground elevation at the shot location, $Z_{S}$ - depth of shot, $E_{R}$ - ground elevation at receiver location, $Z_{R}$ - depth of receiver, $E_{D}$ - datum elevation, $V_{r}$-replacement velocity

When $t_{D}$ is computed, it is then subtracted from the two-way travel time of the trace belonging to that particular source-receiver pair for the implementation of the field statics. The procedure described above supplies a basic view of what field statics entails. However, it is insightful to state that the procedure could in some instances be some-what more complex than described above. Field statics have been successfully implemented to seismic datasets (Huang et al. 2008, Li et al. 2009, Luo et al. 2010, Ponnam et al. 2013).

\section{Refraction statics}

Static anomalies whose spatial wave-lengths are longer than a spread length are not uncommon and, if not corrected, could produce false structures on seismic sections (Marsden 1993b). Applying refraction statics are an effective means for correcting for these long spatial wavelength anomalies and they could also correct for shorter spatial wavelength anomalies (Liu 1998). The wavelength of statics being describe here refers to the width of the lateral (velocity or thickness) change in the weathering layer relative to the spread length (maximum offset). Refraction statics is also a means by which the seismic data is compensated for the effect of the low velocity layer (or weathering layer) (Marsden 1993a, Cox 1999, Zhu et al. 2014).

For the later objective to be achieved, a model of the weathering layer characteristics (thickness and velocity) must be estimated before refraction statics calculation can be performed. A couple of methods have been developed for the computation of refraction statics, ranging from the pioneering approaches of the Plus Minus method (Hagedoorn 1959) to the Slope/Intercept method (Knox 1967), both based on the delay time approximation of refracted travel times to solve for the statics (Yilmaz 2001). More recent approaches include the Generalized Reciprocal methods (Palmer 1981), the Generalized Linear Inversion - GLI (Hampson \& Russell 1984), the Delay Time method which has now been fully developed by Lawton $(1989,1990)$ based on Gardner's idea (Gardner 1939). The Delay Time approach has successfully been adapted in recent times to perform refraction statics (Baker 1999, Butler 2005, Duan 2006, Bridle \& Aramco 2009, Opara et al. 2018). This approach was adopted in the build up to the refraction statics component of the overall statics solution being sought for the currently investigated field.

\section{Residual statics $\left(1^{\text {st }}\right.$ and $\left.2^{\text {nd }}\right)$}

The derivation and application of field statics (also called datum or elevation statics) and the subsequent application of refraction statics does not completely resolve statics anomalies from seismic data (Marsden 1993c, Jing 2003, Yin et al. 2014). These remnant or residual static anomalies are due to discrepancies in the low velocity layer. No matter how well the approaches deployed to derive velocity and thicknesses of the near-surface may be, it is still crucial to state that such models in the actual sense is a some-what simplification of the actual geology because the Earth structure is complex and is nearly impossible to be modeled accurately. The discrepancies between the derived model and the actual Earth model result in errors in the statics correction estimation. The residual statics anomalies are tackled by the implementation of residual statics $\left(1^{\text {st }}\right.$ and $\left.2^{\text {nd }}\right)$ corrections. The residual statics corrections are time shifts applied 
to traces in order to compensate for time delays and the statics model as a function of time and space (Sheriff 1991, Li et al. 2011, Henley 2012).

The residual statics corrections are actually a subset of the statics corrections (Cox 1999). A combination of field statics, refraction statics and residual statics corrections ideally forms a comprehensive and complete statics solution to adequately address the statics problem of seismic field dataset. Residual statics programs are anchored on either linear-surface consistent methods or non-linear surface consistent methods (Russell 1990). The former methods are more widely in use and were the approach used in the study. This approach assumes that the static shifts are time delays that only depend on the source and receiver locations on the surface, not on ray paths in the subsurface. This assumption is valid only if all ray paths, regardless of source-receiver offset, are vertical in the near surface. The surface-consistent assumption is generally good because the weathered layer usually has a low velocity and refraction towards the normal at its base tends to make ray paths vertical.

The total residual time shift, $t_{i j k}$, could be expressed as:

$t_{i j k}=r_{i}+s_{j}+G_{k}+M_{k} x_{i j}^{2}$

where:

$r_{i}$ - the residual static time shift associated with the $i^{\text {th }}$ receiver,

$s_{j}$ - the residual static time shift associated with the $j^{\text {th }}$ source,

$G_{k}$ - the difference in two-way travel time at a reference CMP and the travel time at the $k^{\text {th }} \mathrm{CMP}$,

$M_{k} x_{i j}{ }^{2}$ - the residual moves out that accounts for the imperfect NMO correction.

$G_{k}$ is a structural term, while $M_{k}$ is a hyperbolic term.

The ultimate objective of the residual statics correction procedure is to determine the unknown variables $\left(r_{i}, s_{j}, G_{k}\right.$, and $\left.M_{k}\right)$ from the known variables $\left(t_{i j k}\right.$ and $\left.x_{i j}\right)$. Usually, there are more equations than unknowns; hence, a least-squares approach to minimize the error energy is adopted:

$E=\sum_{i j k}\left[\left(r_{i}+s_{j}+G_{k}+M_{k} x_{i j}^{2}\right)-t_{i j k}\right]^{2}$
Residual statics correction in standard processing practice, involves three progressive phases as detailed in Figure 4.

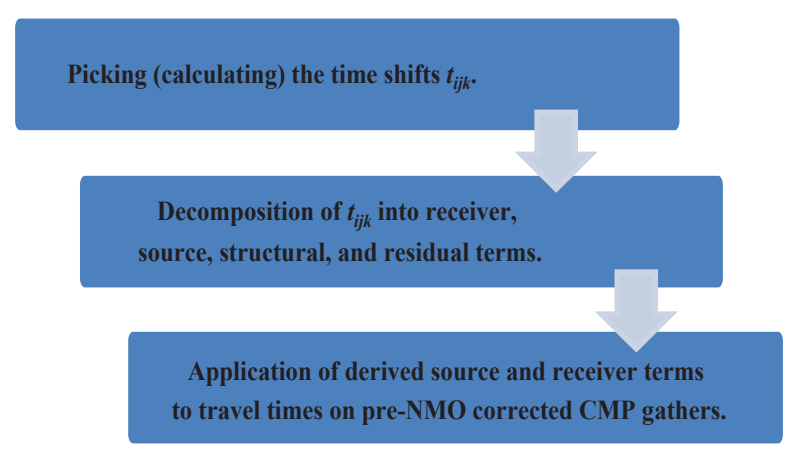

Fig. 4. Processing sequences entailed in the implementation of the residual statics correction

\section{OUR APPROACH TO BUILDING A COMPLETE AND COMPREHENSIVE STATICS SOLUTION}

The approach adopted in our study in the build up to the complete statics solution to address the identified statics problem of the prospect field is summarized with the work flow (Fig. 5).

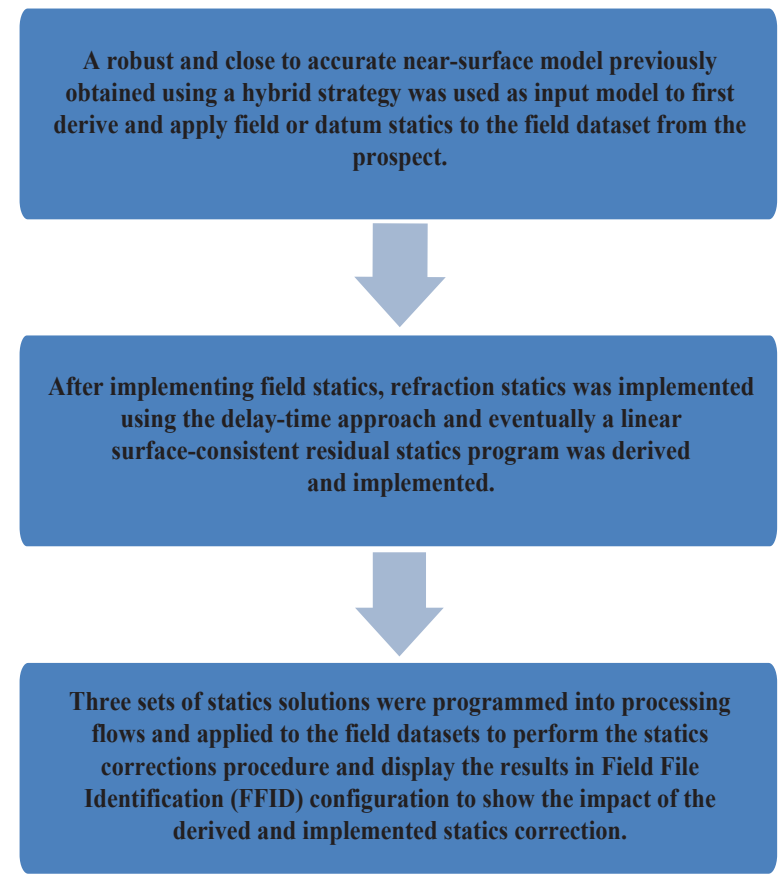

Fig. 5. Processing work flow adopted in the build up to the comprehensive and complete refraction statics solution 


\section{PRESENTATION OF RESULTS AND DISCUSSIONS}

As emphasized earlier, a thorough and comprehensive study has already been carried out in which the near-surface characteristics over the prospect field was clearly established in a previous study (Adizua et al. 2019). That near-surface model is now been employed in the derivation of the comprehensive refraction statics solution that tackles the statics problem of the field. As a follow up to the near-surface model previously obtained, the topography of the prospect field was mapped to justify (in the first instance) the critical need to derive a refraction statics solution for the seismic dataset from this prospect. Figure 6 are plots of offset (source-receiver distance) versus source index number (SIN) over the field in our bid to mirror the topography. Three different views are shown from different orientations and they clearly reveal a rugged and undulating terrain with non-uniform topography which demands field or datum statics (a subset of the comprehensive statics solution) to be derived and applied to mitigate the inducement of non-uniform arrival times from reflectors at different receiver locations.

Wireframe diagrams, Figure 7 were equally generated for the prospect field to reveal the block elevation patterns and trend. As previously established, the elevation is uneven and non-uniform as seen from the wireframe diagrams from their different respective orientations.
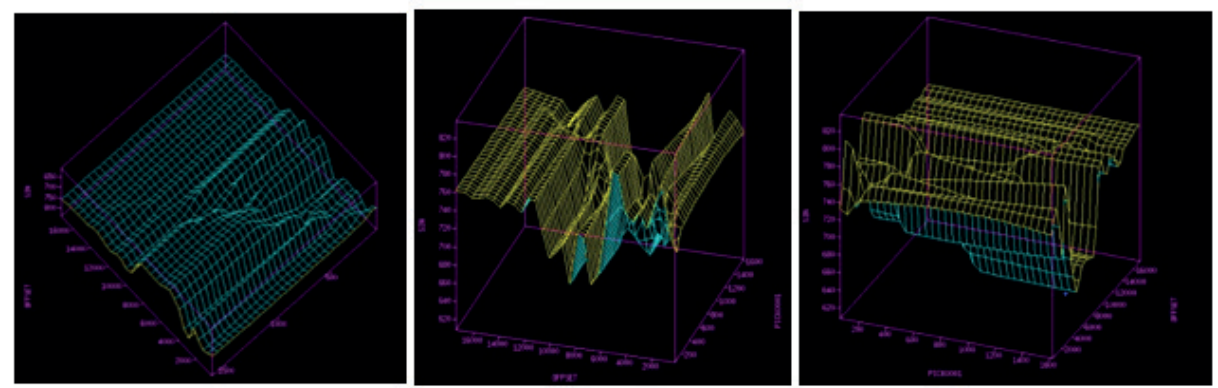

Fig. 6. Offset versus source index number (SIN) plots showing topography
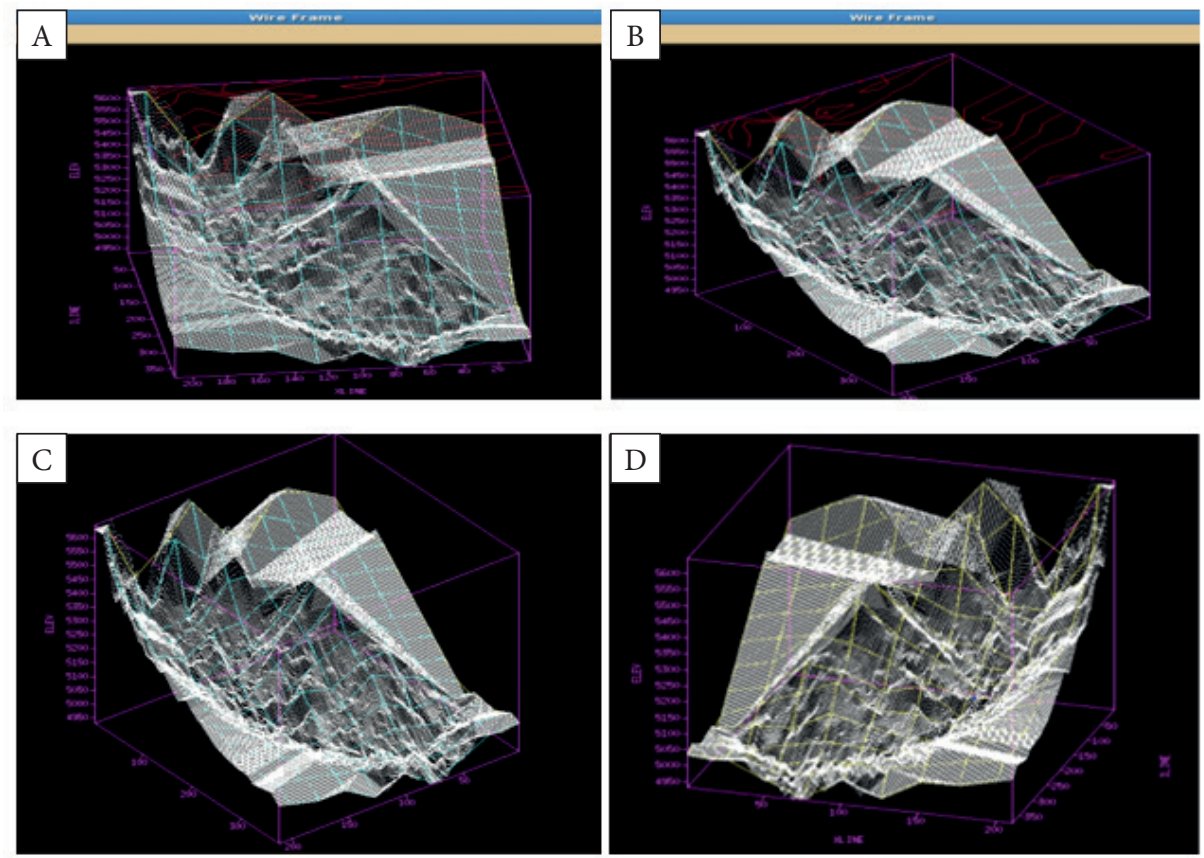

Fig. 7. Wire frame diagrams showing the rugged topography/elevation over the prospect 


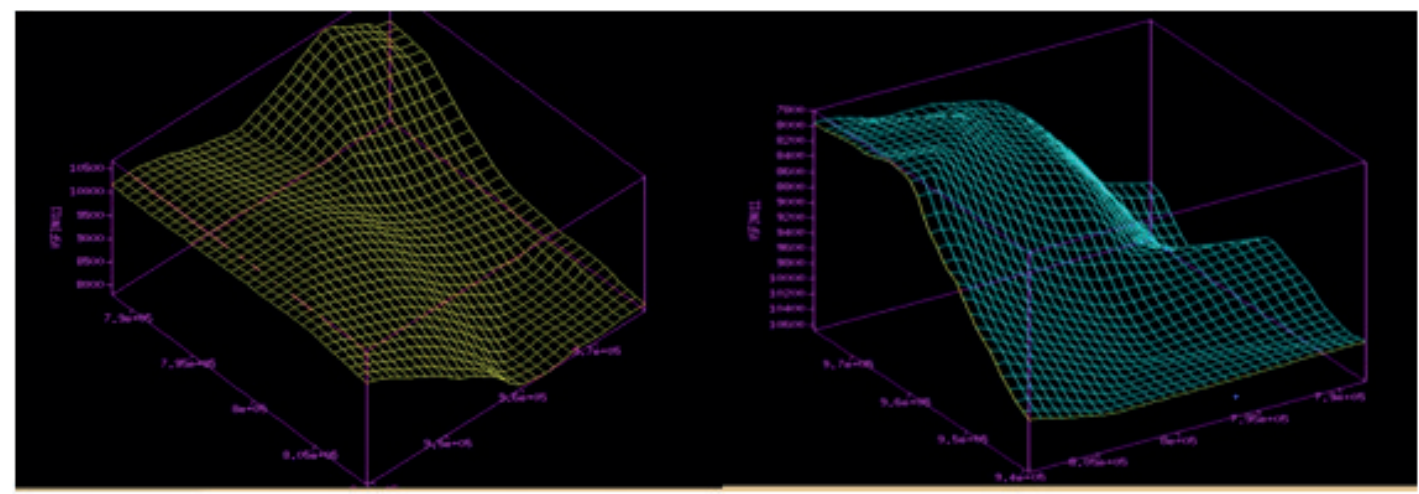

Fig. 8. Refractor velocity wireframe diagram

Refractor velocity wireframe diagrams (Fig. 8) were generated equally in different orientations for the prospect. The diagram basically shows the velocity field over the potentially identified refractors. This velocity field (refractor velocity) is a crucial input parameter in the build up to the sought after comprehensive refraction statics solution.

The near-surface model of the prospect which has previously been generated was inputted together with field header information to derive a comprehensive refraction statics solution that would adequately tackle the statics problem of the prospect. The comprehensive refraction statics solution derived comprised of the field statics, refraction statics, and the residual $\left(1^{\text {st }}\right.$ and $\left.2^{\text {nd }}\right)$ statics. The field statics catered for the uneven or non-uniform elevation statics problem (sometimes called datum statics). The refraction statics was derived and applied to solve the problem of long spatial wavelength statics and a part of the spatial short wavelength statics problem associated with the near-surface heterogeneity of the field. Finally, the residual statics $\left(1^{\text {st }}\right.$ and $\left.2^{\text {nd }}\right)$ solved the remnant spatial short wavelength and long wavelength statics problems that the refraction statics solution could not resolve. The residual statics solution was implemented twice on the dataset to achieve an optimal result. It is imperative to note that the approach to refraction statics derivation and implementation differs from one processing tool to the other.

A set of solutions are now presented which were collectively combined using appropriate flow commands to constitute the complete refraction statics solution that addresses the statics problem already identified for the prospect field. Figure 9 is the source elevation statics solution which is intended to resolve the uneven elevation problem.

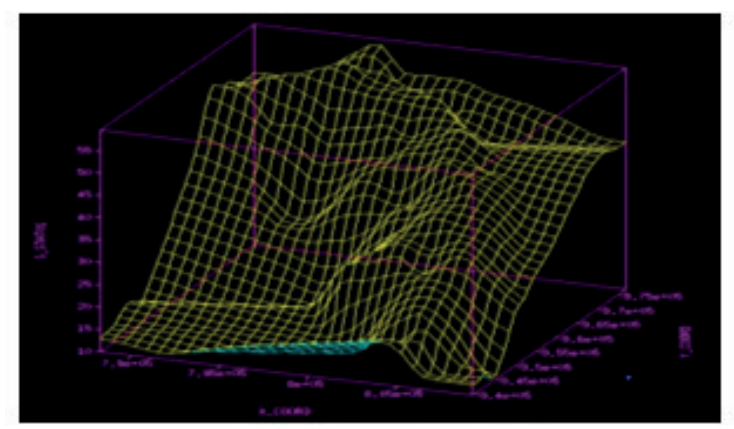

Fig. 9. Source-elevation statics solution

Figure 10 is a schematic diagram showing the source-refraction statics solution derived for the prospect. On close observation, it is noticed that the source and receivers are now being moved to the reference datum plane (the time zero mark) on the vertical axis. The ultimate objective intended to be achieved here is for all the source and receivers to be placed at the chosen or same datum plane.

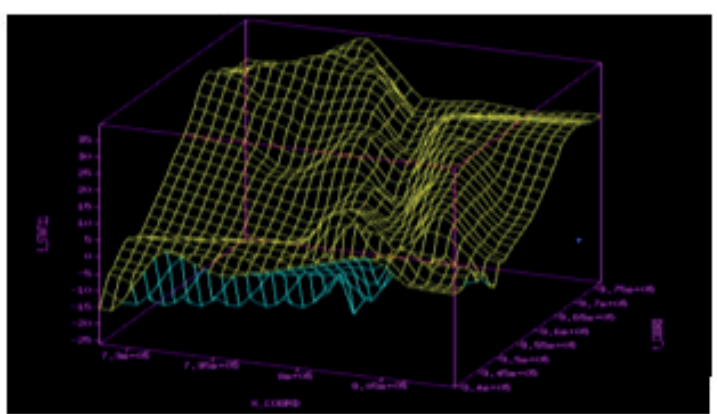

Fig. 10. Source-refraction statics solution 
Figure 11 is a schematic of the source statics from the refraction statics which gives the source positioning and orientation across the investigated field which must be corrected to the reference datum.

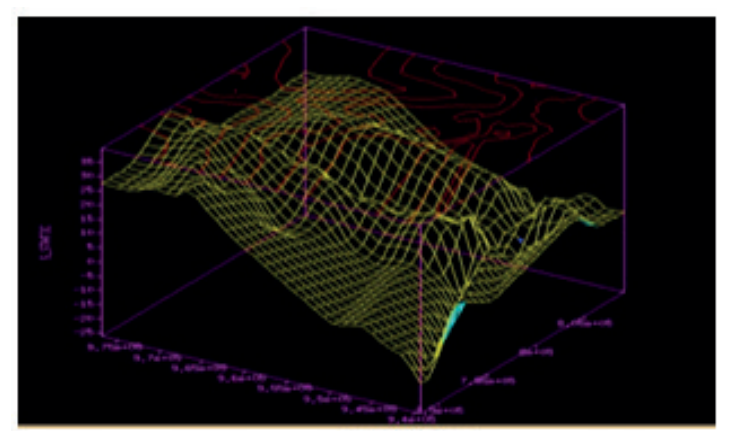

Fig. 11. Source-statics from refraction statics

The solutions so far derived were all adapted to build up the refraction statics solution to final datum (Fig. 12)

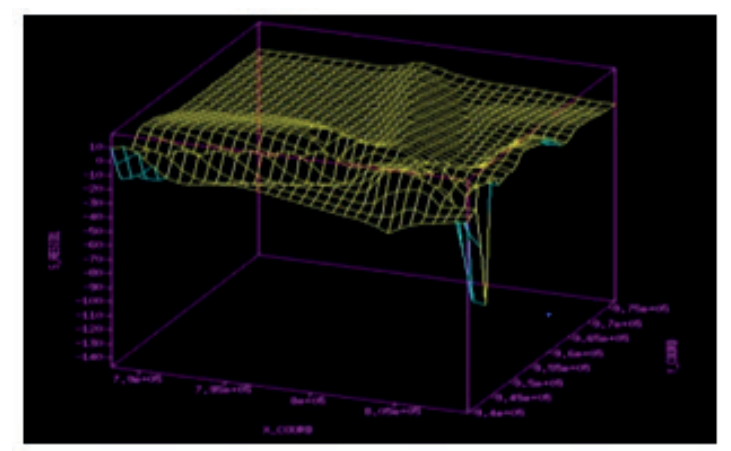

Fig. 12. Refraction statics solution to final datum

It is visible and evident that sources and receivers are almost now aligned at the reference datum except for some trough like structures encountered at the edges of the grid. These anomalies account for unresolved spatial short wavelength and long wavelength statics problems. These unresolved anomalies would subsequently be resolved (moved to the reference datum) when the $1^{\text {st }}$ and $2^{\text {nd }}$ residual statics workflow is applied thereby enabling the source and receivers to be at a defined common datum plane which is the desired and ultimate objective.

In the subsequent parts of this section of the paper, we now present results (before and after application of refraction statics) on seismic gathers in Field File Identification (FFID) format from several shot points. The before and after result for each FFID shot gather is placed side by side, so that on close examination, the problem of the statics would be seen (on the before panel) and the same panel subsequently being corrected for the refraction statics problem (on the after panel). Our idea was basically to first display the seismic data in their respective shot gathers configuration in FFID before any form of processing and then, after the full refraction statics solution was derived and applied to the data, to mirror the dataset again in their respective shot gathers using the same FFID, as our primary focus was to compare and contrast the same shots in their gathers to show how the derived and applied refraction statics solution had successfully solved the statics challenge of the field. Figure 13 shows before and after refraction statics application displays for FFID's 629, 661, 668 and 693.

On closer observation, it is very evident that reflections were becoming more continuous and regular with better energy (amplitude) focus in after displays when the refraction statics solution was applied than in before displays with no derived and applied refraction statics solution. Similarly, Figures 14 and 15 show the before and after display of shot gathers in FFID's $(733,752,758,764,793,797)$ and $(800,853,859)$, respectively. As stated earlier, in a closer examination of the shot gathers it is observed that reflections are now properly moved out and aligned in their proper directions as it ought to. Failure to correct for these distortions in reflection patterns would eventually impede the success of other processing procedures like stacking and migration and would ultimately lead to a false image of the subsurface that would be at variance with the actual geology of the prospect.

Figure 16 displays a collection of selected shots with highlighted markers (arrows) to show regions where the effect or impact of the application of the derived refraction statics solution is most visible. The quality of results achieved at this stage of the processing sequence was superior and more desirable than those achieved in Opara et al. (2018), when both outcomes were compared, this superior result is attributed to the near-accurate and robust near-surface modeling algorithm we adopted for the previous study (Adizua et al. 2019) upon which the refraction statics solution was derived and applied. 
FFID 629 - Before and After Refraction Statics

FFID 661- Before and After Refraction Statics

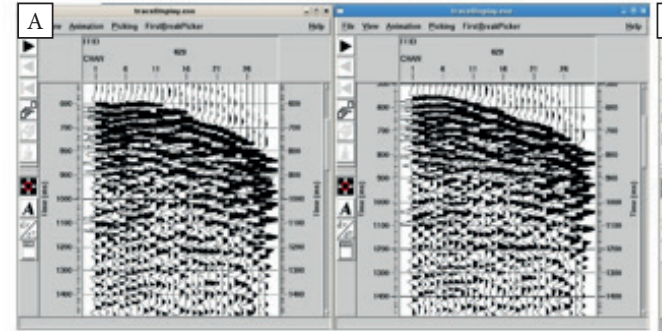

FFID 668 - Before and After Refraction Statics
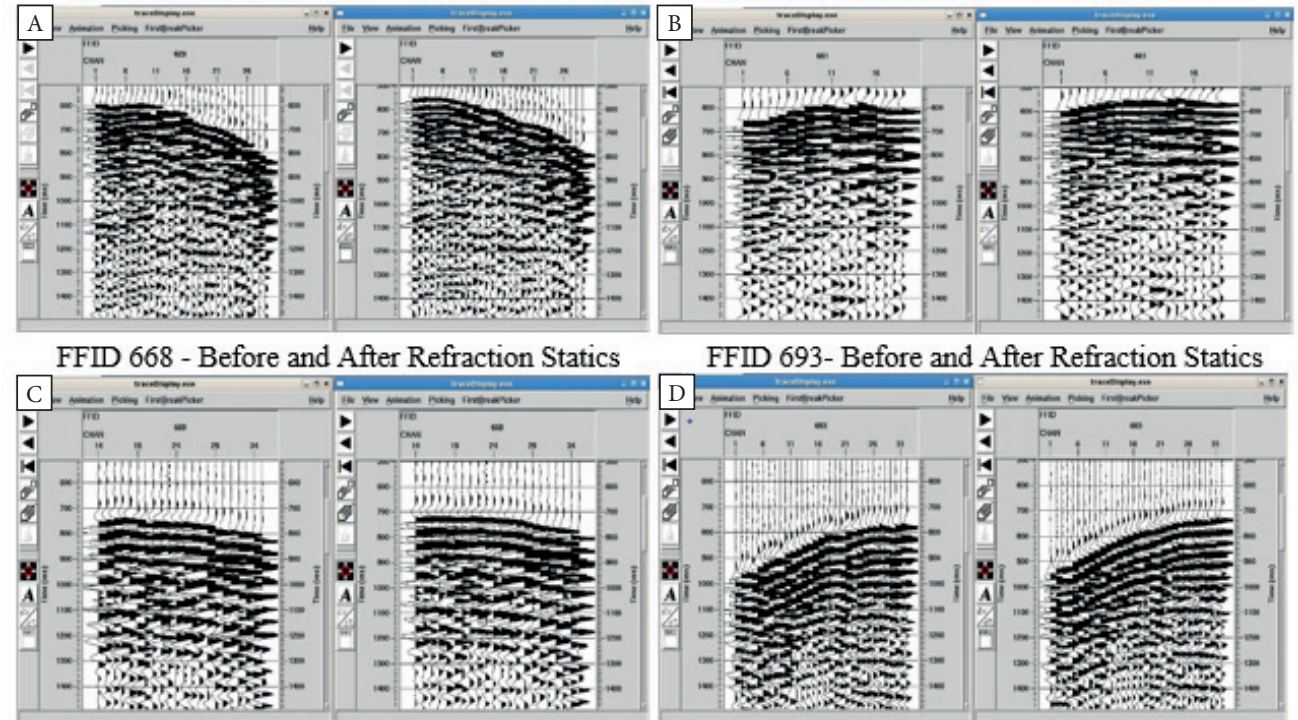

FFID 693- Before and After Refraction Statics

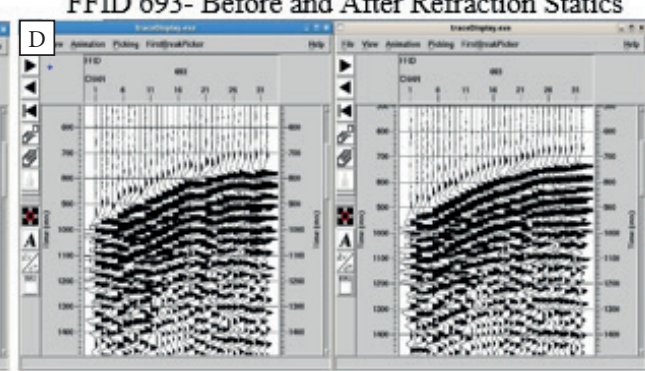

Fig. 13. Derived refraction statics solution applied to shot gathers - FFID 629, FFID 661, FFID 668 and FFID 693
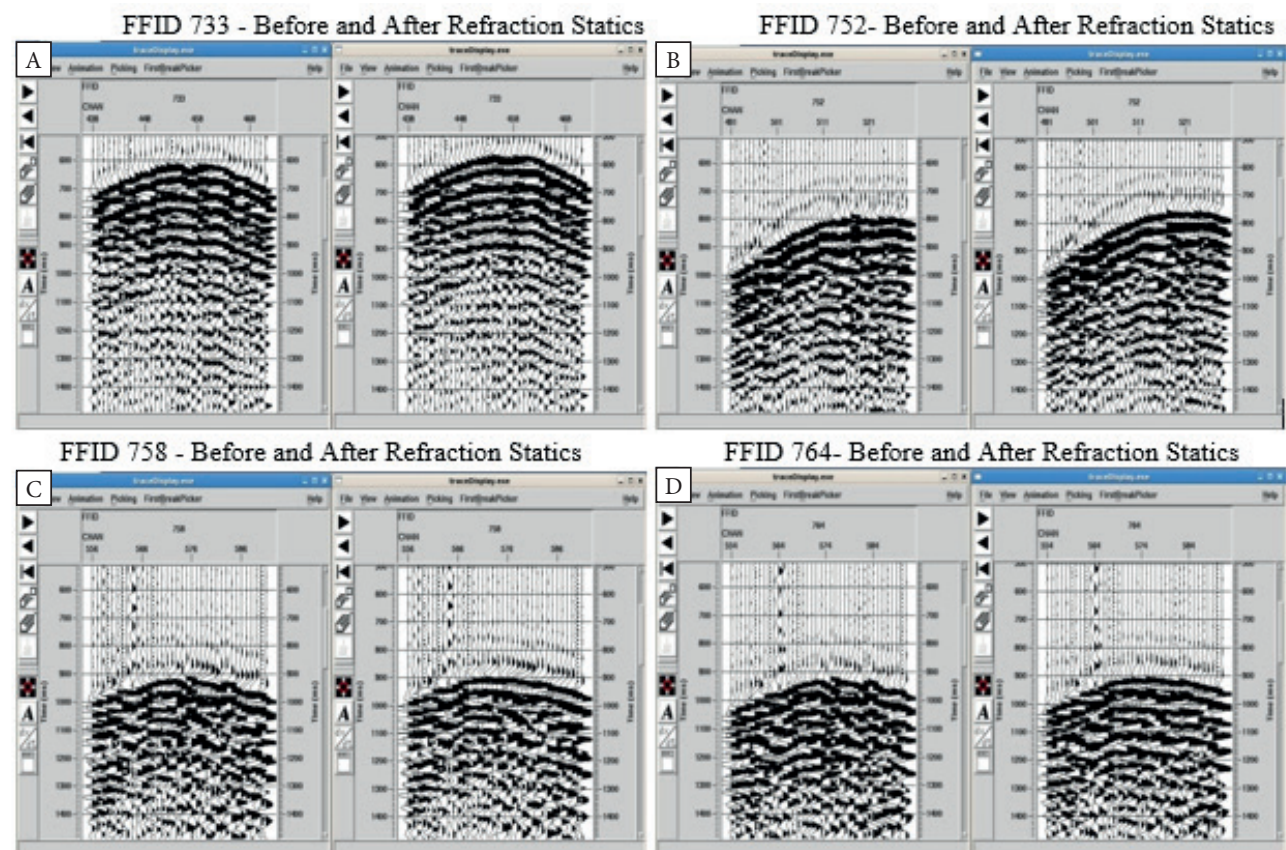

FFID 764- Before and After Refraction Statics

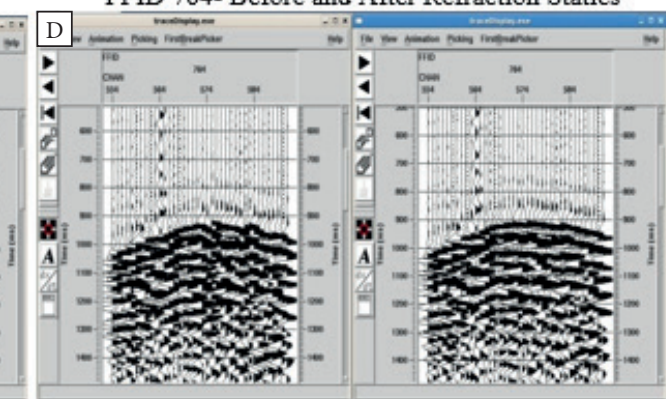

FFID 793 - Before and After Refraction Statics

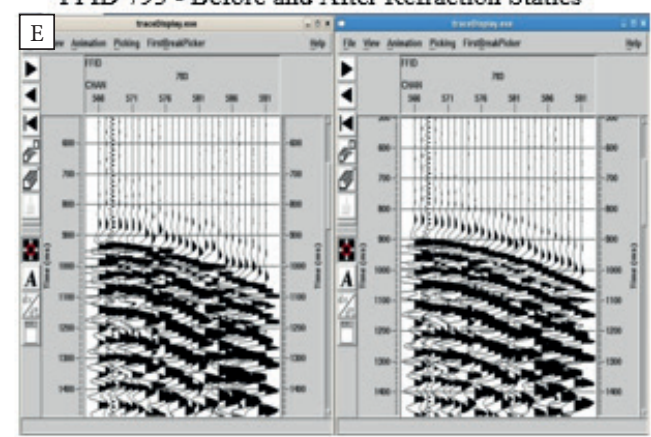

FFID 797-Before and After Refraction Statics

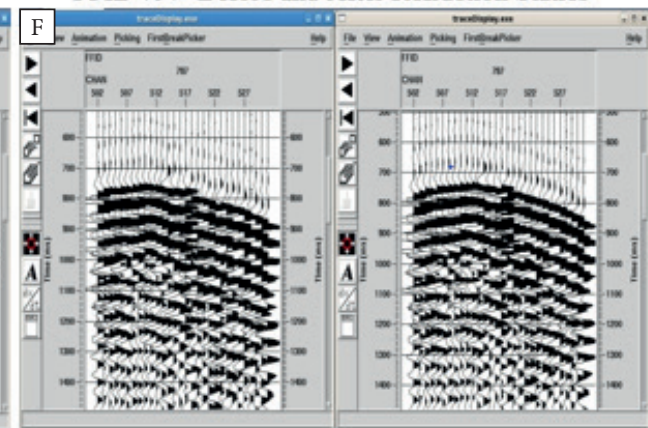

Fig. 14. Derived statics solution applied to shot gathers - FFID 733, FFID 752, FFID 758, FFID 764, FFID 793 and FFID 797 

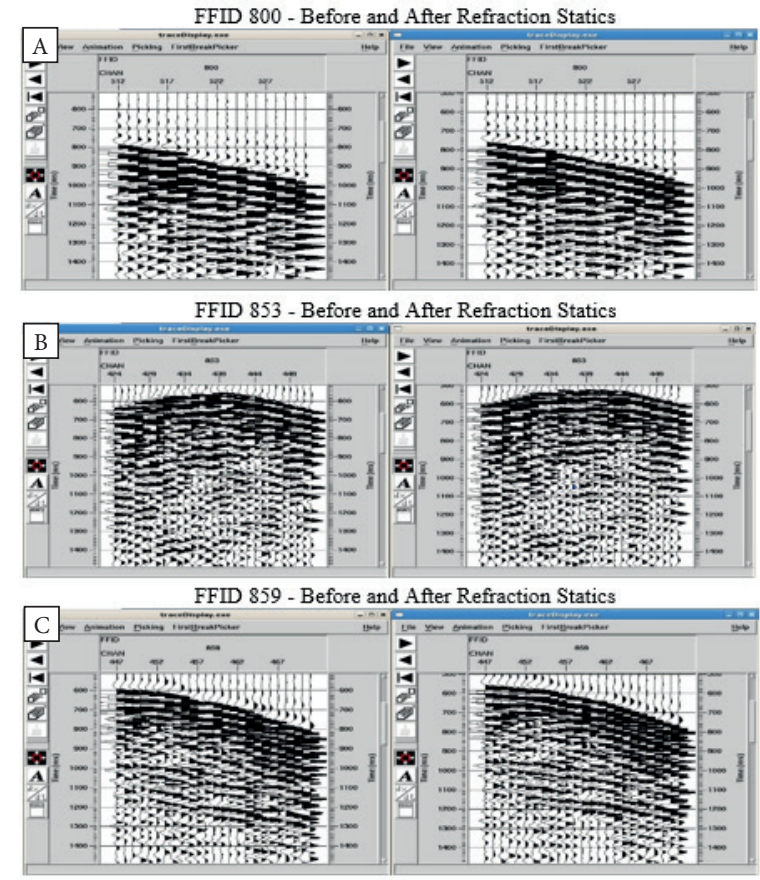

Fig. 15. Derived statics solution applied to shot gathers - FFID 800, FFID 853 and FFID 859
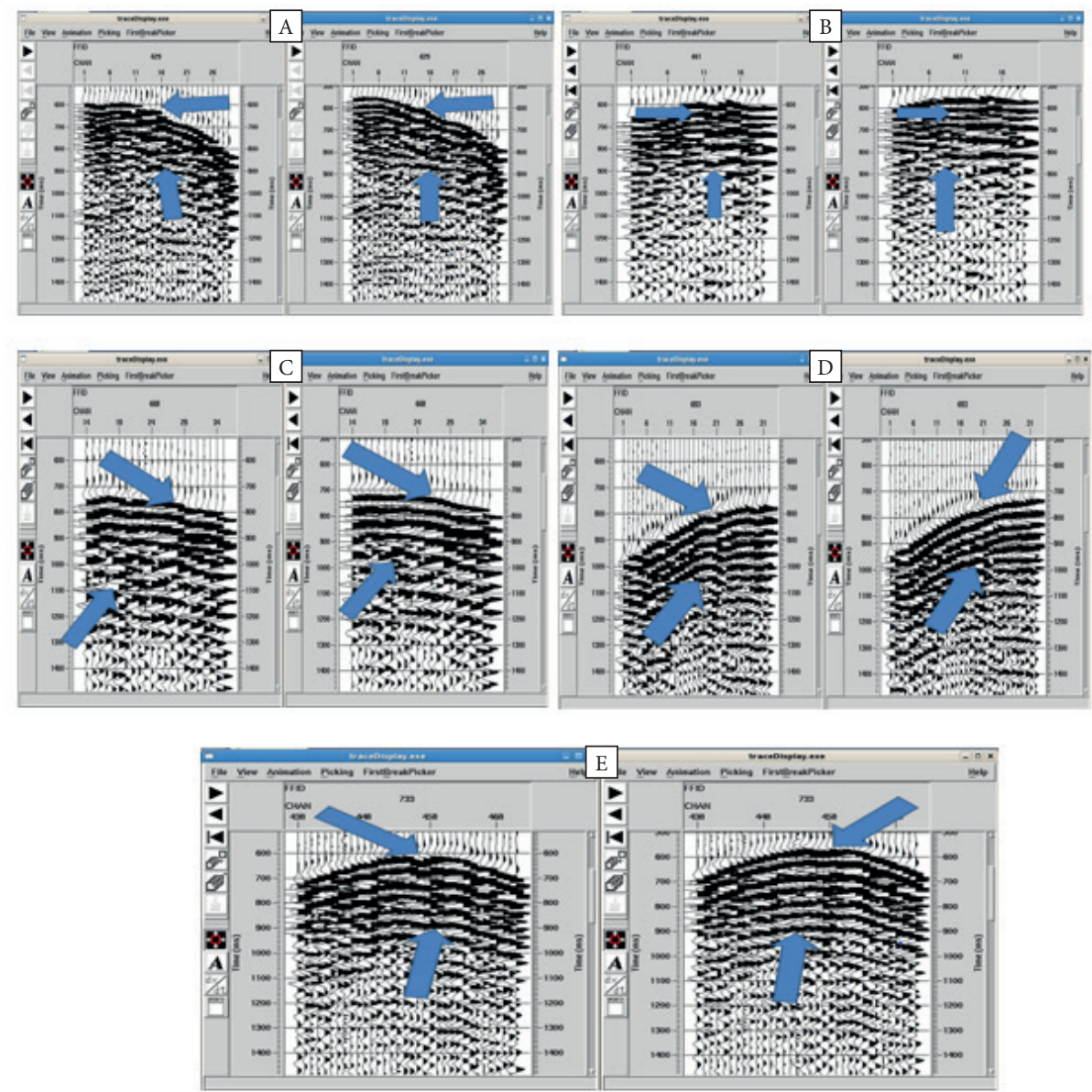

Fig. 16. Selected collection of shots showing with markers (arrows) the resultant effect of the applied refraction statics solution derived on the shot gathers 


\section{CONCLUSION}

The result from a previous study, which successfully imaged and characterized the layer properties of the near-surface $(0-500 \mathrm{~m})$ over the prospect field, was used as a starting model to derive a complete and comprehensive refraction statics solution for acquired 3D seismic reflection data from the prospect field. The complete statics solution derived and applied to the dataset included the field statics, refraction statics, and the $1^{\text {st }}$ and $2^{\text {nd }}$ residual statics. The comprehensive solution was then incorporated into a PROMAX ${ }^{\mathrm{TM}}$ routine using appropriate flows and applied to the seismic datasets to perform the statics correction procedure. The outcome of the derived and implemented statics correction was demonstrated on several shot gathers from the field in FFID configuration. Results from the several shot gathers analyzed after the application of the statics correction across the field showed that traces were adjusted back to their appropriate positions and timings. The reflectors became better aligned and assumed a near-hyperbolic pattern. These are all positive indications that the derived and applied refraction statics solution was the most appropriate for the dataset and that it tackled the statics problem of the prospect field adequately.

Our industry partners are highly appreciated and acknowledged for providing the seismic and uphole survey datasets used for the research and for availing our team of invaluable technical and processing facilities/support. Our affiliate Institutions, the University of Port Harcourt, Nigeria and the Nnamdi Azikiwe University, Nigeria are acknowledged for providing the teaching and research platforms and the enabling environment that spurred the research. This study could not have been realized without the insightful contributions of some intelligent and experienced "egghead" geoscientists with whom we had very meaningful discussions. Their insightful comments and arguments are highly appreciated. The editorial and review team of the Geology, Geophysics and Environment Journal are appreciated for their excellent peer review system. Their comments and suggestions greatly improved the manuscript. Worthy of mention are Prof. Anna Świerczewska, Maciej Dwornik and
Urszula Aleksander-Kwaterczak who were always available to offer assistance.

\section{REFERENCES}

Adizua O.F., Anakwuba E.K. \& Onwuemesi A.G., 2019. A Hybrid approach to near-surface imaging and characterization for an onshore Niger Delta prospect field. Journal of Earth Sciences and Geotechnical Engineering - JESGE, 9, 1, 1-14.

Baker G.S., 1999. Processing near-surface seismic reflection data: A primer. Course Notes Series, 9, SEG Books, Tulsa, Oklahoma, USA.

Bridle R. \& Aramco S., 2009. Delay-Time refraction methods applied to a 3D seismic block. The Leading Edge, 28, 2, 212-215.

Butler D.K. (ed.), 2005. Near-surface Geophysics. Investigations in Geophysics, 13, SEG Books, Tulsa, Oklahoma, USA

Cox M., 1999. Static corrections for seismic reflection surveys. Geophysical References, 9, SEG Books, Tulsa, Oklahoma, USA.

Deere J., 2009. Introduction to this Special Section - Statics. The Leading Edge, 28, 2, 190-191.

Duan Y.Q., 2006. Residual static corrections based on refraction survey. Oil and Gas Prospecting - OGP, 41, 2, 32-35.

Gardner L.W., 1939. An areal plan of mapping subsurface structures by refraction shooting. Geophysics, 4, 4, 247259.

Hagedoorn J.G., 1959. The Plus-Minus method of interpreting seismic reflection sections. Geophysical Prospecting, 7, 158-182.

Hampson D. \& Russell B., 1984. First-Break interpretation using generalized inversion. Journal of the Canadian Society of Exploration Geophysicists, 20, 40-54.

Henley D.C., 2012. Interferometric applications in static corrections. Geophysics, 77, 1, 1-13.

Huang M.Z., Feng Z.Y. \& Zhou D.T., 2008. Directly iterated statics correction method in Offset Domain and its application. Progress in Exploration Geophysics, 31, 2, $122-128$.

Jing X.L., 2003. Two steps solution methods for big residual static corrections. Oil and Gas Prospecting - OGP, 38, 1, 22-26.

Keho T.H. \& Kelamis P.G., 2012. Focus on Land Seismic Technology: The Near-surface Challenge. The Leading Edge, 31, 62-68.

Knox W.A., 1967. Multilayer near-surface refraction computations. [in:] Musgrave A.W. (ed.), Seismic Refraction Prospecting, Society of Exploration Geophysicists, 197-216.

Lawton D.C., 1989. Computation of refraction statics corrections using first-break travel time differences. Geophysics, 54, 1289-1296.

Lawton D.C., 1990. A nine-component refraction statics experiment. [in:] SEG Technical Program Expanded Abstracts 1990, Society of Exploration Geophysicists, 1089-1092.

Li L., Chen X.J. \& Jing X.L., 2011. Multi-scale inversion algorithm for seismic residual statics correction and its application. Xinjing Petroleum Geology, 32, 4, 402-405. 
Li P., Feng Z. \& Li Z., 2009. Statics correction technology and applications in complex areas of western China. The Leading Edge, 28, 2, 1384-1386.

Liu L.S., 1998. Constrained first arrival pick up and firstbreak residual static correction. Oil and Gas Prospecting - OGP, 35, 5, 604-610.

Luo Y.W., Yang J. \& Duan W.X., 2010. Comparing between several statics correction methods. Petroleum Instruments, 24, 5, 41-43.

Marsden D., 1993a. Statics corrections - a review, part I. The Leading Edge, 12, 1, 43-49.

Marsden D., 1993b. Statics corrections - a review, part II. The Leading Edge, 12, 2, 115-120.

Marsden D., 1993c. Statics corrections - a review, part III. The Leading Edge, 12, 3, 210-216.

Opara C., Adizua O.F. \& Ebeniro J.O., 2018. Application of static correction in the processing of $3 \mathrm{D}$ seismic data from onshore Niger Delta. Universal Journal of Geoscience, 6, 1, 1-7.

Palmer D., 1981. The Generalized Reciprocal Method of seismic refraction interpretation. Geophysics, 36, 1508-1518.

Ponnam S., Navin M., Sarvind R., Sudhakar M. \& Dutta N.M., 2013. Field Statics estimations: A case history from North Assam Shelf, Assam, India. [in:] 10 ${ }^{\text {th }}$ Biennial International Conference and Exposition - Kochi 2013, Society of Petroleum Geophysicists, 287-291.

Russell B.H., 1990. Statics correction - A tutorial. CSEG Recorder, 14, 3, 16-30.

Sheriff R.E., 1991. Encyclopedic Dictionary of Exploration Geophysics. $3^{\text {rd }}$ ed., Geophysical References, 1, Society of Exploration Geophysicists.

Short K.C. \& Stauble A.J., 1967. Outline of the Geology of Niger Delta. American Association of Petroleum Geologists Bulletin, 51, 761-779.

Uko E.D., Ekine A.S. \& Ebeniro J.O., 1992. Weathering Structure of the East-Central Niger Delta, Nigeria. Geophysics, 57, 9, 1228-1233.

Yilmaz O., 2001. Seismic Data Analysis: Processing, Inversion, and Interpretation of Data. Investigations in Geophysics, 10, SEG Books, Tulsa, Oklahoma, USA.

Yin C., Xiong X.J. \& Zhang B.L., 2004. The Study of using the fourth accumulated component in residual static corrections. Gas Industry, 24, 12, 48-50.

Zhu X.S., Gao R., Li Q.S., Guan Y., Lu Z. \& Wang H., 2014. Static corrections methods in the processing of deep reflection seismic data. Journal of Earth Science, 25, 2, 299-308. 